\title{
Improvement of ZVS Range and Current Quality of the Nine-Switch Single-Stage AC-DC Converter
}

\author{
Kawsar Ali, Member, IEEE, Sunil Kumar Dube, Student Member, IEEE, Pritam Das, Senior Member, IEEE, \\ Jimmy Chih-Hsien Peng, Member, IEEE, and Dan Rogers, Member, IEEE
}

\begin{abstract}
The nine-switch single-stage three-phase AC-DC isolated converter integrates a three-phase active front end (AFE) AC-DC converter and a three-phase high frequency galvanic isolated DC-DC converter in one stage, leading to a devicecount reduction of $25 \%$ compared to an equivalent two-stage configuration. The advantage of the nine-switch converter can be truly realized if it can achieve similar efficiency and input current quality as a two-stage converter. In this paper a design methodology is proposed which ensures zero-voltage switching (ZVS) of the bottom and the middle switches of the nineswitch converter for the entire line-cycle, and also reduces its input current total harmonic distortion (THD) below 5\%. By implementing space vector pulse-width modulation (SVPWM) the DC-link voltage of the nine-switch converter is reduced to the level of an equivalent two-stage converter. The analytical claims are verified with a $3 \mathrm{~kW}$ laboratory prototype operating at $400 \mathrm{~V}$ AC input, $800 \mathrm{~V}$ DC-link voltage, and $380 \mathrm{~V}$ isolated DC output voltage.
\end{abstract}

Index Terms - back-to-back converter, loss computation, nineswitch converter, single-stage converter, twelve-switch converter, zero-voltage switching

\section{INTRODUCTION}

$\mathbf{M}$ IGRATION towards a DC based data center requires generation of a regulated and isolated DC voltage of $380 \mathrm{~V}(400 \mathrm{~V})$ [1]-[3] or $48 \mathrm{~V}$ [4] from the AC mains. This is usually achieved using an active front-end (AFE) power factor corrected (PFC) AC-DC rectifier followed by an isolated DCDC converter, with a power decoupling DC-link between them. A close-to-unity power factor and a less than 5\% input current total harmonic distortion (THD) are some of the common specifications expected from such converters [5]. For $3 \mathrm{~kW}$ or more rated power, a three-phase AC-DC rectifier is typically used for the PFC stage, while the DC-DC stage is often interleaved. The interleaving of the DC-DC stage also reduces the output ripple, and hence, the output filter size [6]-[8], which is a major concern in high current applications like data centers.

There have been many efforts [5], [9]-[14] to combine the two stages of AC-DC isolated power conversion into a single stage. However, in almost all the cases, these single-stage AC-DC converters operate in discontinuous conduction mode

Kawsar Ali (corresponding author) and Dan Rogers are with the Department of Engineering Science, University of Oxford, United Kingdom, e-mail: kawsar.ali@eng.ox.ac.uk, dan.rogers@eng.ox.ac.uk.

Sunil Dube and Pritam Das are with the Department of Electrical and Computer Engineering, Binghamton University, NY, USA, e-mail: sdube2@binghamton.edu,pdas@binghamton.edu.

Jimmy Peng is with the Department of Electrical and Computer Engineering, National University of Singapore, Singapore, e-mail: jpeng@nus.edu.sg.
(DCM) of the input current, which poses many design and control challenges [10], [13]. Reference [15] proposed a novel three-phase AC-DC isolated converter in this context, which, despite being a single-stage topology, features continuous conduction mode (CCM) of the input current. The converter presented therein is based on a nine-switch bridge topology [16]-[23], which is considered as a reduced-switch-countequivalent (25\% reduction) of a twelve-switch two-stage backto-back (BTB) topology [22], [24] where the front stage is a three-phase six-switch boost rectifier and the back stage is a parallel combination of three half-bridge DC-DC isolated converters. A unique three-carrier modulation technique is also implemented in [15] which realizes the interleaved operation of the DC-DC stage without affecting the PFC operation. The integrated DC-DC stage comprises three asymmetrical pulsewidth modulated half-bridge (APWM HB) series resonant converters [25], [26], which reduce the converter losses by soft-switching, and make the design of the whole converter relatively simple due to constant frequency operation (as compared to frequency-controlled resonant converters).

However, the nine-switch single-stage three-phase AC-DC isolated converter available in literature so far has the following major drawbacks which need to be addressed.

1) The DC-link voltage of the converter is higher than usual. In particular, the DC-link voltage of the nineswitch converter presented in [15] has to be more than $1000 \mathrm{~V}$ for an $\mathrm{AC}$ input of $400 \mathrm{~V}$; whereas, for a conventional AFE boost PFC rectifier, the DC-link voltage is only about $800 \mathrm{~V}$ [5]. While a higher-than$1000 \mathrm{~V}$ DC-link may be less of a problem with the commercial availability of high-voltage rated $(1200 \mathrm{~V}$ and 1700V) Silicon Carbide (SiC) MOSFETs, finding a suitable energy storage capacitor can be an issue. Even the series connection of two electrolytic capacitors rated at $400 \mathrm{~V} \sim 500 \mathrm{~V}$ is not enough in this case.

2) The bottom and the middle switches of the nine-switch converter fail to achieve zero-voltage switching (ZVS) over the entire line-cycle.

3) The THD of the input line currents is more than 5\% even at full-load condition. This is not acceptable in today's data center power systems, which require input current THD below 5\% in the load range of 50\% 100\% of the rated capacity [5].

In essence, even though the nine-switch converter combines a three-phase AFE rectifier and three DC-DC isolated converters in a single-stage, its previous designs could not deliver 
the key performance metrics, such as less than 5\% current THD, and ZVS of its switches to the maximum extent. To address these issues, this paper revisits the design of the nine-switch converter, and presents an improved nine-switch AC-DC converter with high frequency three phase galvanic isolation, which achieves full-range ZVS of the bottom and the middle switches, and also reduces the input current THD below 5\%. Contrary to the claims in [15], [27], it is shown in this work that, increasing the switching frequency is not the only solution for reducing the line current THD; rather, the ZVS of the bottom switch has a greater effect on it. By implementing space vector pulse-width modulation (SVPWM) the DC-link voltage of the converter is reduced to $800 \mathrm{~V}$ for an $\mathrm{AC}$ input of $400 \mathrm{~V}$.

Therefore, the contribution of this paper is two fold. Firstly, it extends the soft switching range of the devices of the nine-switch single-stage AC-DC converter leading to improved efficiency. And secondly, it reduces the the input current THD of the converter below 5\% without increasing the switching frequency. A comparison of performance and cost with the existing works is also presented to highlight the advantages of the proposed design.

\section{TOPOLOGY AND BASIC OPERATION}

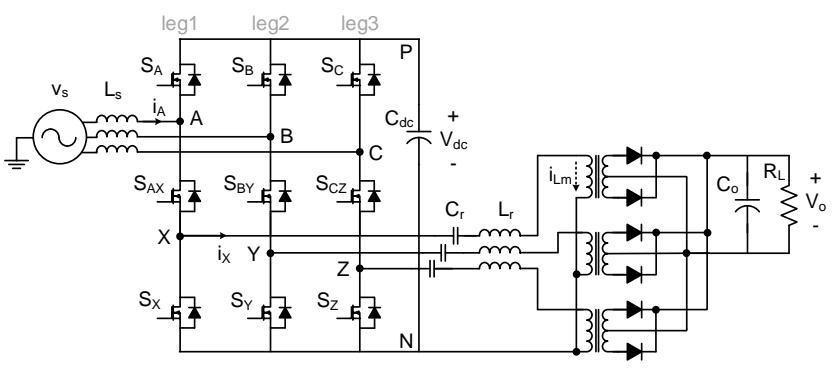

Fig. 1. The nine-switch single-stage three-phase AC-DC isolated converter as proposed in [15].

The nine-switch single-stage three-phase AC-DC isolated converter is shown in Fig. 1. This topology merges a "threephase AFE boost PFC rectifier", and three parallel connected "APWM half-bridge DC-DC resonant converters", which are sometimes referred to as the "upper converter" and the "lower converter" respectively. The upper converter controls the power factor by controlling the input currents in $\mathrm{CCM}$ and maintains a constant DC-link voltage, while the lower converter generates an isolated and regulated output DC voltage from the DC-link voltage. The merging of the two converters is facilitated by the sharing of the three middle switches between them. This section presents the switching constraint arising from this merger and a modulation scheme to overcome it.

\section{A. Switching Constraint}

There is a fundamental switching constraint in any nineswitch converter [16]-[23] because of the presence of three switches in a leg - it is impossible to have the lower converter pole-voltage $v_{X N}$ higher than the upper converter polevoltage $v_{A N}$. To comply with this constraint, it is necessary that the upper terminal modulation references $\operatorname{Ref}_{A, B, C}$ is always higher than the lower terminal modulation references $\operatorname{Ref}_{X, Y, Z}$. This is illustrated in Fig. 2(a) where the references are given appropriate DC-shifts so that $\operatorname{Ref}_{A, B, C}$ are placed above $\operatorname{Ref}_{X, Y, Z}$. The modulation references for the first leg of the nine-switch converter of Fig. 1 can be defined as follows.

$$
\left\{\begin{array}{l}
\operatorname{Ref}_{A}=M_{A} \sin \omega t+M_{O A} \\
\operatorname{Ref}_{X}=-M_{O X}=2 D-1
\end{array}\right.
$$

where, $\omega$ is the angular line frequency; $M_{A}, D$ are the modulation indices of the upper and the lower converters respectively; and $M_{O A}, M_{O X}$ are the DC offsets given to the modulation references. As a corollary to the above switching constraint, the nine-switch converter must also satisfy the following inequality, which leads to the higher-than-usual DClink voltage [16]-[23]:

$$
M_{A}+D \leqslant 1
$$

\section{B. Modulation Scheme}

Fig. 2(a) also depicts the three-carrier modulation used for the proposed converter, where the carriers for the three legs of the converter $v_{\text {carr },[A, B, C]}$ are $120^{\circ}$ phase-shifted from each other. This helps to realize the interleaved operation of the DC-DC stage (lower converter) without affecting the PFC operation of the upper converter. As a result, the high frequency ripple in the final isolated DC output voltage $V_{o}$ is decreased by three times as compared to a single-carrier modulation, reducing the required value of the output filter capacitor $C_{o}$ for a given allowable ripple content in $V_{o}$.

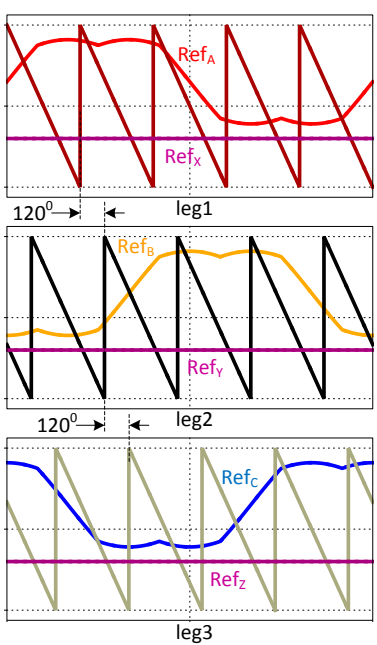

(a)
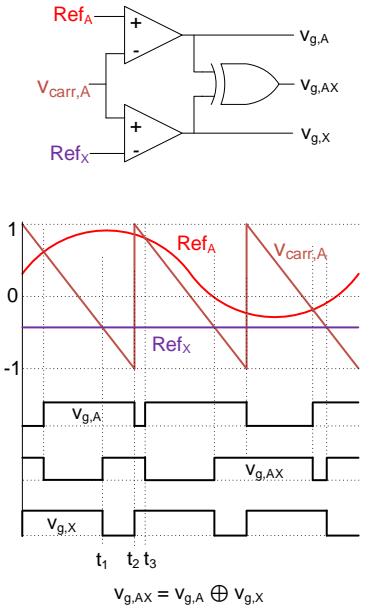

(b)
Fig. 2. Modulation technique of the converter. (a) Reference and carrier signals for the three legs. Note the $120^{\circ}$ phase difference of the carriers for the three legs, and the DC-shifts of the signals $\operatorname{Ref}_{A, B, C}$ above the signals $\operatorname{Ref}_{X, Y, Z}$. (b) Gate pulse generation logic for the switches of the first leg of the converter.

The PWM logic for generation of gate pulses for the three switches of the first leg of the converter is shown in Fig. 2(b). Two modulating waveforms $\operatorname{Ref}_{A}$ and $\operatorname{Ref}_{X}$ are compared with a common sawtooth carrier to generate the gate pulses 
for the top switch $\left(v_{g, A}\right)$ and the bottom switch $\left(v_{g, X}\right)$ respectively, while the gate pulse for the middle switch $\left(v_{g, A X}\right)$ is obtained from the exclusive-OR (XOR) logic combination of the top and bottom switch gate pulses

$$
v_{g, A X}=v_{g, A} \oplus v_{g, X}
$$

This is done to prevent short-circuit of the DC bus, while conforming to the switching constraint mentioned previously. The XOR operation also enables a time-multiplexed operation of the middle switches to serve the upper converter and the lower converter. For example, in Fig. 2(b), the middle switch $S_{A X}$ is serving the lower converter as its top switch (complementary of $S_{X}$ ) from $t_{1}$ to $t_{2}$, and it is serving the upper converter as its bottom switch (complementary of $S_{A}$ ) from $t_{2}$ to $t_{3}$. Because of such time-multiplexing, the upper converter and the lower converter are decoupled and independent in a control sense [17], [20], [23].

\section{Space Vector Pulse-Width Modulation}

As shown in (2), because of the less-than-unity modulation index for the PFC stage, the DC-link voltage of the nineswitch converter is usually higher than the conventional AFE boost PFC rectifier. SVPWM is a well-established technique used to better utilize the DC-link voltage in a three-phase rectifier/inverter system [28], [29], which has been extended many times to the nine-switch converter as well [18], [19], [30]. Because of the decoupled behavior of the upper converter and the lower converter, two standard SVPWM blocks for the upper and the lower converter, synchronized to each other, can be implemented [30]. These will produce the gate pulses for the top and the bottom switches; the gate pulse for the middle switch can then be generated by the XOR of top and bottom switch pulses in order to comply with the switching constraint discussed earlier.

A similar approach has been followed for the converter discussed here (Fig. 1). However, only one SVPWM block is needed here as the lower converters are simple DC-DC converters. To facilitate the implementation of the SVPWM in a micro-controller, the sinusoidal references $\operatorname{Ref}_{A, B, C}$ have to be generated from the time steps $t_{A, B, 0}$ given by the space vector modulator. The mathematical operations required for this are detailed in [31]. A simplified version of the overall control architecture for the converter is shown in Fig. 3.

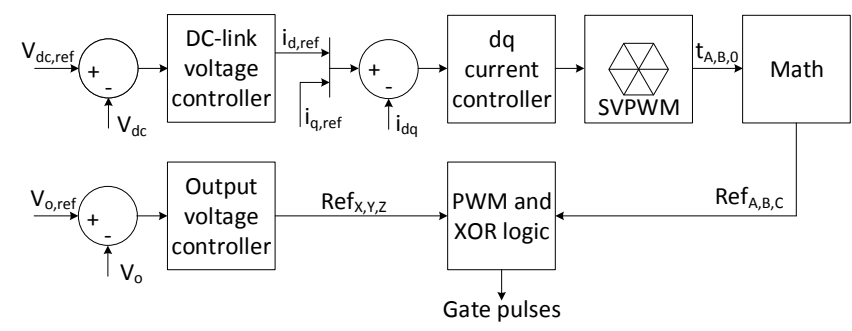

Fig. 3. Simplified control architecture for the converter. Note that the generation of $\operatorname{Ref}_{A, B, C}$ from $t_{A, B, 0}$ is detailed in [31].
The DC-link voltage $\left(V_{d c}\right)$ of the converter with the implementation of SVPWM [28], [32] is given by

$$
V_{d c}=0.86 \times \frac{2 \sqrt{2} v_{s, r m s}}{\sqrt{3} M_{A}}=0.86 \times V_{d c, S P W M}
$$

where $V_{d c, S P W M}$ is the DC-link voltage with conventional sinusoidal pulse-width modulation (SPWM). Therefore, the DC-link voltage of the nine-switch converter could be brought down to $800 \mathrm{~V}$ (from $950 \mathrm{~V}$ ), which is close to a standard AFE rectifier with an $\mathrm{AC}$ input of $400 \mathrm{~V}$.

\section{Full-Range ZVS of Bottom And Middle SWITCHES}

As discussed in the introduction, the bottom and the middle switches of the nine-switch converter should, by design, always have ZVS turn-on. However, it has been shown in [15] that these two switches undergo hard turn-on around the positive peak region of the corresponding phase current. The reason is the addition/cancellation of the two terminal currents through the switches of the corresponding leg of the converter as explained in Fig. 4.

If the positive peak of the phase current $\left(I_{A}\right)$ is greater than the positive peak of the corresponding resonant tank current $\left(I_{X}\right)$ before the turn-on of the bottom switch, the difference $\left(I_{A}-I_{X}\right)$ flows through the body diode of the top switch. This leaves the output capacitance $\left(C_{o s s}\right)$ of the bottom switch charged, and therefore, it undergoes a hard turn-on. This is shown in Fig. 4(a).

If the positive peak of the phase current $\left(I_{A}\right)$ is less than the positive peak of the corresponding resonant tank current $\left(I_{X}\right)$ before the turn-on of the bottom switch, the difference $\left(I_{X}-I_{A}\right)$ flows through the body diode of the bottom switch itself after discharging its output capacitance $\left(C_{o s s}\right)$. Thus the bottom switch achieves ZVS in this case as shown in Fig. 4(b).

A similar explanation can be made for the case of the middle switch as well.

Therefore, the condition for ensuring ZVS of the bottom and the middle switches of the nine-switch single-stage AC-DC converter over the entire line-cycle is to have the the positive peak of the resonant tank current greater than the peak of the corresponding phase current. This can be achieved by proper design of the converter parameters as proposed in the next subsection.

\section{A. Derivation of ZVS Condition}

Assuming ideal zero-loss operation, the peak of the input phase current $I_{A}$ of the nine-switch converter is similar to that of a three-phase AFE boost rectifier, and is given by

$$
I_{A}=\sqrt{2} \frac{V_{o}^{2} / R_{L}}{\sqrt{3} v_{s, r m s}},
$$

where, $V_{o}$ and $R_{L}$ are the output voltage and the load resistance respectively. The input RMS voltage (line-to-line) $v_{s, r m s}$ is related to the DC-link voltage $\left(V_{d c}\right)$ by

$$
v_{s, r m s}=\frac{\sqrt{3} M_{A} V_{d c}}{0.86 \times 2 \sqrt{2}} .
$$




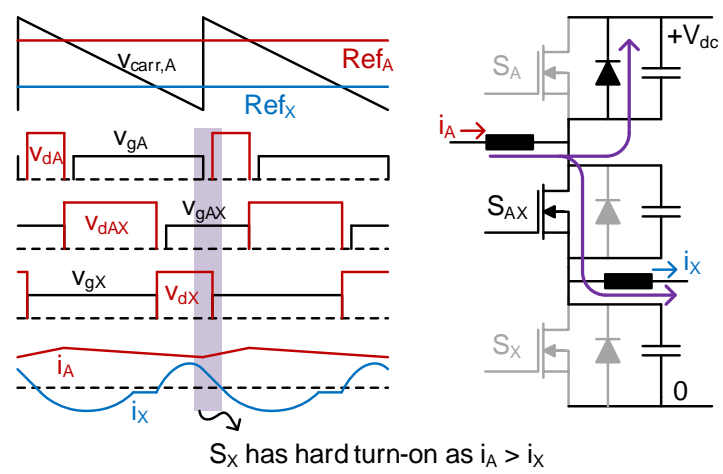

(a) Bottom switch misses ZVS because the phase current is higher than the peak of the resonant tank current.

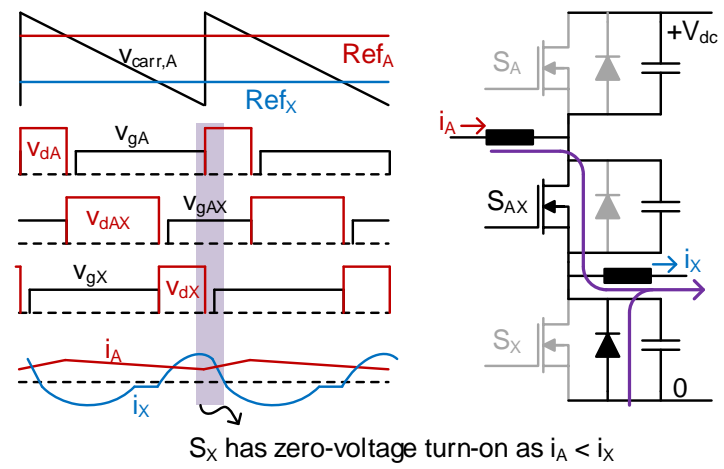

(b) Bottom switch undergoes ZVS because the phase current is lower than the peak of the resonant tank current.

Fig. 4. Explanation of ZVS condition for the bottom switches of the nineswitch single-stage AC-DC converter.

Now, to have the minimum possible DC-link voltage in the nine-switch converter [24], we need

$$
M_{A}=1-D .
$$

Substituting (7) into (6), and then to (5), we have

$$
I_{A}=\frac{0.86 \times 4 V_{o}^{2} / R_{L}}{3(1-D) V_{d c}}
$$

Similarly, assuming negligible magnetizing current, the peak of the resonant tank current $I_{X}$ is same as that of an APWM HB series resonant converter [26], and is given by

$$
I_{X}=V_{d c} \sqrt{\frac{C_{r}}{L_{r}}}
$$

which can be further simplified as

$$
I_{X}=\frac{\pi^{2} V_{o}^{2}}{3 Q_{0} R_{L} V_{d c}(1-\cos 2 \pi D)} .
$$

Here $Q_{0}$ is the full-load quality factor of the resonant tank, which is always chosen as $\pi / 2$ for the APWM HB converter with magnetizing current assisted ZVS [26]. Substituting $Q_{0}=\pi / 2$ into (10), we have

$$
I_{X}=\frac{2 \pi V_{o}^{2} / R_{L}}{3 V_{d c}(1-\cos 2 \pi D)} .
$$

As explained before, for the bottom and the middle switches to always achieve ZVS turn-on, we must have $I_{X}>I_{A}$. Substituting from (8) and (11), we have

$$
\pi(1-D)>0.86 \times 2(1-\cos 2 \pi D) .
$$

A MATLAB solution of (12) is obtained as $0 \leq D \leq 0.273$ and $0.919 \leq D \leq 1$ as shown in Fig. 5(a). It is obvious that $D \geq 0.919$ is not a practical choice. Therefore, it can be concluded that the only condition necessary for achieving ZVS turn-on of the bottom and the middle switches of the converter is " $D$ has to be chosen below 0.273 ". Fig. 5(b) shows the variation of $I_{X}$ and $I_{A}$ w.r.t. $D$ for two different rated power designs of the converter. It is further corroborated form Fig. 5(b) that, the condition $D \leq 0.273$ holds true irrespective of the rating of the converter.

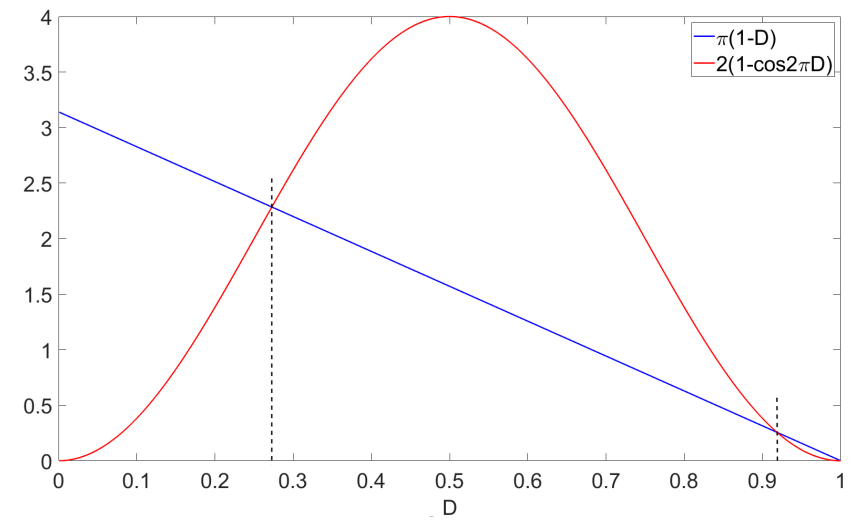

(a) MATLAB solution of (12).

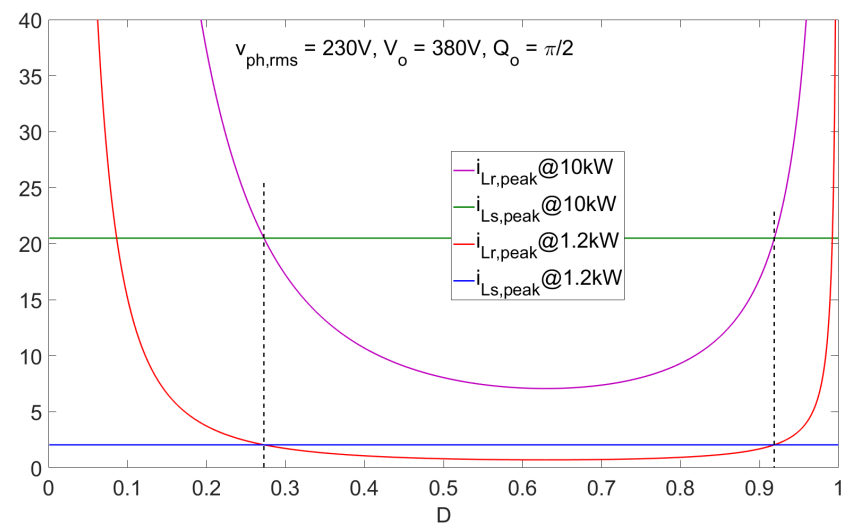

(b) Verification for different rated power design.

Fig. 5. Condition for ZVS of the bottom and the middle switches of the nine-switch single-stage AC-DC converter over the entire line-cycle.

It should be noted that (11) is obtained with an assumption of zero magnetizing current in the transformers. However, in practice, for ZVS of its switches, this topology uses a finite amount of magnetizing current, which flows in the same direction as $I_{X}$ and increases its value above that calculated from (11). It has been found that for $D=0.28$, as used in 
this work, $I_{X}$ is still greater than $I_{A}$ (because of the added magnetizing current) and the ZVS of the bottom and the middle switches of the nine-switch single-stage three-phase AC-DC isolated converter are ensured over the entire linecycle.

It may be noted that the choice of $D=0.28$ limits the control range of duty-cycle of the APWM half-bridge DC-DC resonant converters, which form the "lower converter" part of the proposed nine-switch converter. Therefore, their design point has to be shifted to $D=0.28$ (instead of the ideal case of $D=0.5$ ) to cover the entire range of load variation [26].

\section{B. Effect of ZVS on Input Current Harmonic Distortion}

The effect of dead-time on the harmonic distortion of the pole voltage and current of an active full-bridge rectifier/inverter is a well-known phenomenon [33], [34]. Similarly, the soft-switching of the switches of a leg during the deadtime also determines the presence of some of the low-order harmonics in the pole voltage and current.

As illustrated in Fig. 6, the ZVS turn-on of the bottom switch affects the shape of the average of the upper pole voltage $\left(\left\langle v_{A N}\right\rangle\right)$ of the converter. During the positive half of the phase-a input current, if both the top and the bottom switches have ZVS turn-on, there is a gain in voltage for $v_{A N}$ on its rising edge, which is offset by the equal voltage loss on its falling edge, as shown in Fig. 6(a). Therefore there is no distortion of the average pole voltage $\left\langle v_{A N}\right\rangle$ in this case.

On the other hand, if the bottom switch misses ZVS for some part of the positive half of the phase-a input current, there is gain of voltage for $v_{A N}$ on both of its rising and falling edge. This results in the distortion of the average pole voltage $\left\langle v_{A N}\right\rangle$ as shown in Fig. 6(b), which, in turn, distorts the phase-a input current accordingly.

Therefore, achieving ZVS for the bottom and the middle switches of the converter over the entire line-cycle not only reduces its overall switching loss, but also helps in reducing its input current THD without the need of increasing the switching frequency. This has been verified with simulation and experimental results in the coming sections.

As a summary of the discussion in this section, the softswitching regions over a line-cycle of the input current for the converter are shown in Fig. 7. This will be used in the next section for calculation of losses.

\section{Simulation And Loss Analysis}

The operation of the converter with the proposed design methodology was simulated in PLECS with the design parameters as listed in Table I. The reader is referred to [15], [26] for a complete design procedure of all the other components of the converter. This section highlights some of the key simulation results and presents the estimation of losses in the different components of the converter.

To demonstrate the effect of the lower converter duty ratio $D$ on the shaping of the input current, two separate simulations were carried out - one with $D<0.3$, and the other with $D>0.3$. Fig. 8 shows the phase-a input current for the two cases, where the distortion can be noted near the positive peak

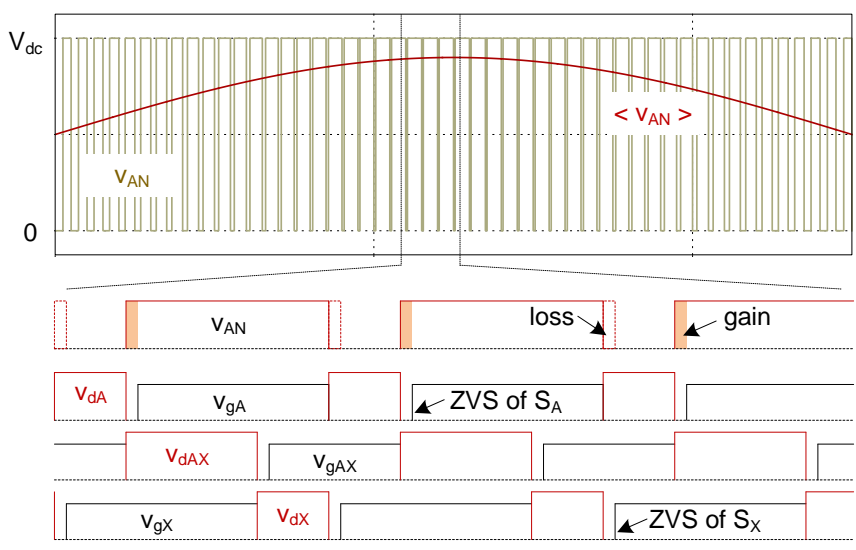

(a) With ZVS turn-on of the bottom switch.
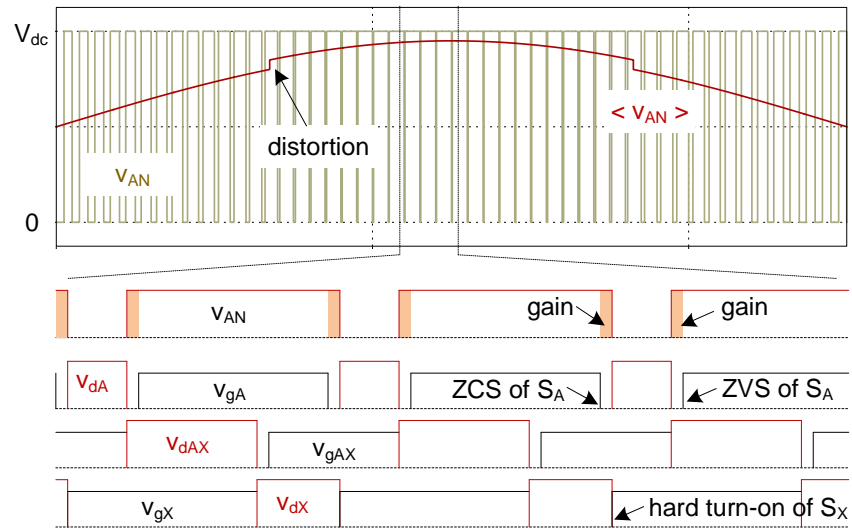

(b) Without ZVS turn-on of the bottom switch.

Fig. 6. Illustration of effect of ZVS turn-on of the bottom switch on the shape of average pole voltage $\left\langle v_{A N}>\right.$ of the converter.

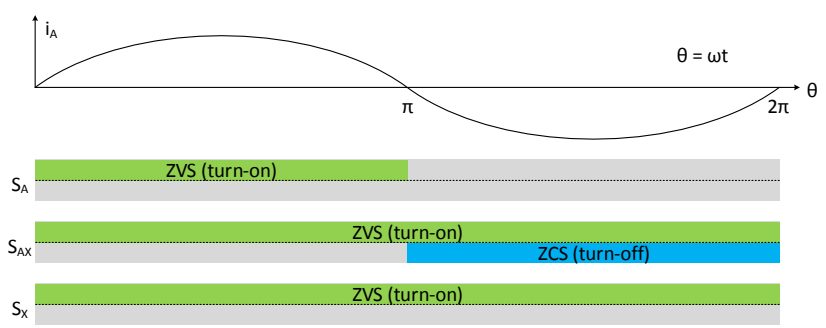

Fig. 7. Soft-switching regions of the switches of one leg over a line-cycle of the input current. Note that, unlike the previous works, the bottom and the middle switches achieve ZVS over the entire line-cycle.

of the current for the case of $D>0.3$. As explained in the previous section, this distortion is due to the hard-switching (turn-on) of the bottom switch. No such distortion is seen for the case of $D<0.3$, due to the ZVS of the bottom switch in the entire line-cycle.

Fig. 9 shows the simulated demonstration of soft-switching of the three switches of the first leg of the converter at different instances of one line-cycle of the input phase-a current. This is in complete agreement with Fig. 7 and the discussions in the previous section.

Some of the important components used for building the 
TABLE I

DESIGN PARAMETERs OF THE CONVERTER

\begin{tabular}{lll}
\hline Parameter name & Symbol & Value \\
\hline Rated power & $P_{o}$ & $3 \mathrm{~kW}$ \\
Input voltage (line-line, rms) & $v_{s}, r m s$ & $400 \mathrm{~V}, 50 \mathrm{~Hz}$ \\
DC-link voltage & $V_{d c}$ & $800 \mathrm{~V}$ \\
Output voltage & $V_{o}$ & $380 \mathrm{~V}$ \\
Switching frequency & $f_{s}$ & $60 \mathrm{kHz}$ \\
Load resistance & $R_{L}$ & $48 \Omega$ \\
Input boost inductance & $L_{s}$ & $2 \mathrm{mH}$ \\
DC-link capacitance & $C_{d c}$ & $0.33 \mathrm{mF}$ \\
Output filter capacitance & $C_{o}$ & $0.48 \mathrm{mF}$ \\
Upper converter duty ratio & $M_{A}$ & 0.7 \\
Upper converter modulation offset & $M_{O A}$ & 0.3 \\
Lower converter duty ratio & $D$ & 0.28 \\
Lower converter modulation offset & $M_{O X}$ & -0.44 \\
Transformer turns ratio & $N$ & 0.85 \\
Resonant inductance & $L_{r}$ & $354 \mu \mathrm{H}$ \\
Resonant capacitance & $C_{r}$ & $20 \mathrm{nF}$ \\
Switch output capacitance & $C_{o s s}$ & $51 \mathrm{pF}$ \\
Deadtime & $t_{d}$ & $300 \mathrm{~ns}$ \\
Transformer magnetizing inductance & $L_{m}$ & $1.6 \mathrm{mH}$ \\
\hline
\end{tabular}

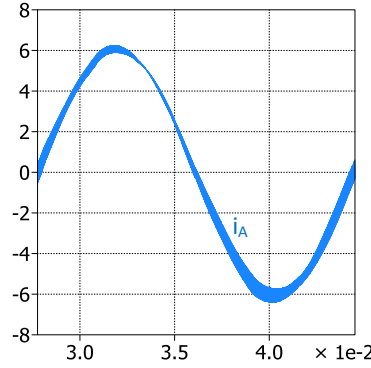

(a) With $D=0.28$.

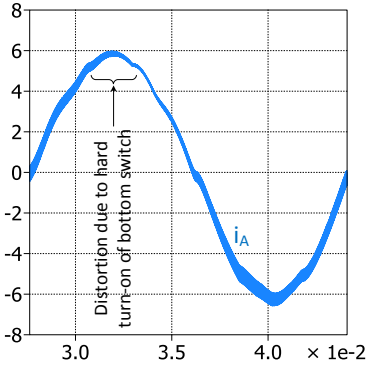

(b) With $D=0.35$.
Fig. 8. Simulated waveform of phase-a current showing the effect of $D$ on the harmonic distortion of input current. Vertical axes are current magnitude (A), and horizontal axes are time (s).

experimental prototype of the converter are listed in Table II. The details of the inductors and transformers are presented separately in Table III. The loss analysis presented in this section uses data from these tables.

TABLE II

IMPORTANT COMPONENTS USED IN THE PROTOTYPE

\begin{tabular}{ll}
\hline Component name & Part number \\
\hline MOSFET & C2M0080120D \\
Output Diode & IDH05G120C5XKSA1 \\
MOSFET driver & ACPL-P343-500E \\
Resonant capacitor & B32672L8103J000 \\
Output capacitor & B32774D4505K000, UPZ2G121MHD6 \\
DC-link capacitor & B32774D0205K000, ALC10A331DH550 \\
Controller & TMS320F28335 \\
\hline
\end{tabular}

\section{A. Switch Turn-on Loss}

The switch currents of the first leg of the converter for different switching intervals are listed in Table IV. It is also important to note the instantaneous current values during switch commutations as shown in Table V.
TABLE III

Details of Magnetic Components Used in the Prototype

\begin{tabular}{ll}
\hline Component & Details \\
\hline Boost inductor core & MP5812MPFC(2605SA1) \\
Boost inductor winding & 120 turns of AWG14 copper wire \\
\hline Transformer core & PQ35/35-3C95 \\
Primary winding & 32 turns of $140 / 39$ litz wire \\
Secondary winding & $(40+40)$ turns of $105 / 39$ litz wire \\
\hline Resonant inductor core & PQ35/35-3C95 \\
Resonant inductor winding & 48 turns of $140 / 39$ litz wire \\
\hline
\end{tabular}

TABLE IV

SWITCH CURRENTS OF THE CONVERTER

\begin{tabular}{llll}
\hline State $\left(S_{A}, S_{A X}, S_{X}\right) \rightarrow$ & $(0,1,1)$ & $(1,0,1)$ & $1,1,0)$ \\
\hline$i_{S A}$ & 0 & $-i_{A}$ & $-\left(i_{A}-i_{X}\right)$ \\
$i_{S A X}$ & $i_{A}$ & 0 & $i_{X}$ \\
$i_{S X}$ & $\left(i_{A}-i_{X}\right)$ & $-i_{X}$ & 0 \\
\hline
\end{tabular}

Based on Table V and Fig. 7, the average turn-on losses of the switches can be obtained as follows, where $t_{r}$ is the risetime of the MOSFET. The other symbols carry their meanings from Table I.

$$
\begin{gathered}
P_{o n, S A}=\frac{1}{2 \pi} \int_{\pi}^{2 \pi} 0.5 f_{s}\left(C_{o s s} V_{d c}^{2}+V_{d c} t_{r}\left(-I_{A} \sin \theta\right)\right) d \theta \\
P_{o n, S A X}=P_{o n, S X}=0
\end{gathered}
$$

\section{B. Switch Turn-off Loss}

Again, based on Table $\mathrm{V}$ and Fig. 7, the average turn-off losses of the switches can be obtained as follows, where $t_{f}$ is the rise-time of the MOSFET.

$$
\begin{gathered}
P_{o f f, S A}=\frac{1}{2 \pi} \int_{0}^{2 \pi} 0.5 V_{d c} t_{f} f_{s}\left(I_{X}-I_{A} \sin \theta\right) d \theta \\
P_{o f f, S A X}=\frac{1}{2 \pi} \int_{0}^{\pi} 0.5 V_{d c} t_{f} f_{s} I_{A} \sin \theta d \theta \\
P_{o f f, S X}=0.5 V_{d c} t_{f} f_{s} I_{L m}
\end{gathered}
$$

where $I_{L m}=N V_{o}\left(0.5-\theta_{1} / \pi\right) /\left(2 f_{s} L_{m}\right)$ is the peak of the magnetizing current and $\theta_{1}=\tan ^{-1}\left(\frac{\sin 2 \pi D}{1-\cos 2 \pi D}\right)$ from [26]. Again, the symbols carry their meanings from Table I. Note that the middle switch $S_{A X}$ has zero-current switching (ZCS) turn-off during the negative half of the phase-a current.

Equations (13) to (17) are clearly different from the previous work because the ZVS regions of the switches have changed.

TABLE V

Commutation Currents of The Switches of THE Converter

\begin{tabular}{lll}
\hline Switch & Event & Commutation Current \\
\hline$S_{A}$ & turn-on & $-i_{A}$ \\
$S_{A}$ & turn-off & $-\left(i_{A}-I_{X}\right)$ \\
$S_{A X}$ & turn-on & $I_{L m}$ \\
$S_{A X}$ & turn-off & $i_{A}$ \\
$S_{X}$ & turn-on & $\left(i_{A}-I_{X}\right)$ \\
$S_{X}$ & turn-off & $-I_{L m}$ \\
\hline
\end{tabular}



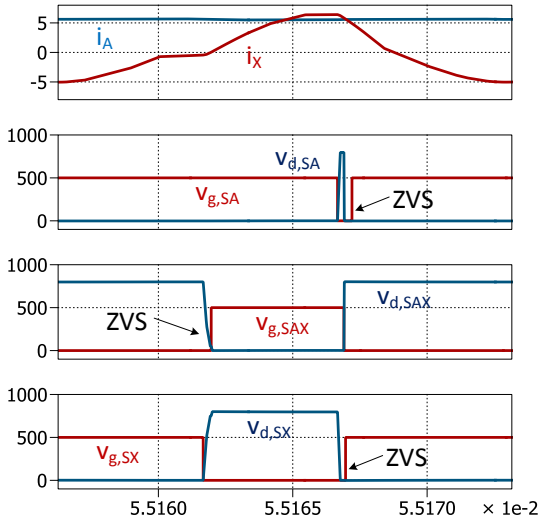

(a) For $\theta \approx \pi / 2$.
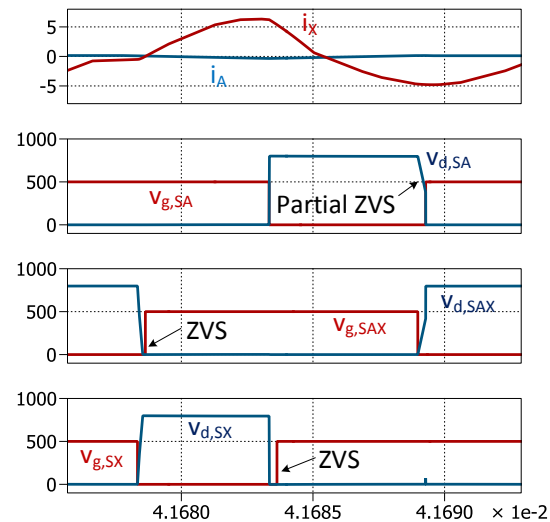

(b) For $\theta \approx 0$ and/or $\theta \approx \pi$.
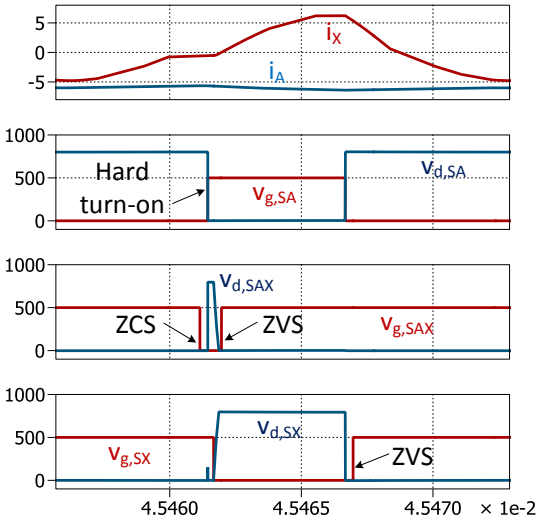

(c) For $\theta \approx 3 \pi / 2$.

Fig. 9. Identification of soft-switching of the three switches of the first leg of the converter at different instances of the input phase-a current from PLECS simulation. The variable $\theta$ is defined in Fig. 7. Vertical axes are current (A) and voltage (V) magnitude, and horizontal axes are time (s). Note that the gate voltages are not to scale.

\section{Switch Conduction Loss}

The conduction loss of any switch can be calculated as $I_{r m s}{ }^{2} R_{D S, O N}$, where $I_{r m s}$ is the RMS current of the switch and $R_{D S, O N}$ is its ON-state resistance. The expressions for RMS currents of the switches of the converter are listed below [22], [24]. The symbols carry their meanings from Table I.

$$
\begin{gathered}
I_{S A, r m s}=(0.5) \sqrt{\left(1+M_{O A}\right) I_{A}^{2}+\left(1-M_{O X}\right) I_{X}^{2}} \\
I_{S A X, r m s}=(0.5) \sqrt{\left(1-M_{O A}\right) I_{A}^{2}+\left(1-M_{O X}\right) I_{X}^{2}} \\
I_{S X, r m s}=(0.5) \sqrt{\left(1-M_{O A}\right) I_{A}^{2}+\left(1+M_{O X}\right) I_{X}^{2}}
\end{gathered}
$$

Fig. 10 shows the breakdown of the losses in the switches of one leg of the converter at its rated power of $3 \mathrm{~kW}$. Note that the total losses in the MOSFETs amount to $1.4 \%$ of the rated power in this case, whereas in [15] it was about $2 \%$ of the rated power.

The expressions for all the other losses in the converters are not shown here, as they are either straight forward or they can be obtained from the datasheets. Fig. 11 shows the distribution of power losses at different components of the converter at its rated power of $3 \mathrm{~kW}$. With a total loss of $144.23 \mathrm{~W}$, the theoretical efficiency of the converter at full load is $95.2 \%$.

\section{EXPERIMENTAL RESULTS AND DISCUSSIONS}

A laboratory prototype of the converter as shown in Fig. 12 was built and tested with the same design parameters listed in Table I. This section discusses the results obtained from the experiments.

Fig. 13 shows the main input and output voltage/current waveforms of the converter at its rated power of $3 \mathrm{~kW}$ with $400 \mathrm{~V}$ (line-to-line) three-phase AC input. A near-unity power factor and a regulated $380 \mathrm{~V}$ output DC voltage can be noted from the figure.

To demonstrate balanced three-phase operation, Fig. 14 shows the three-phase input currents and phase-a voltage along with the DC-link voltage and the output DC voltage of the

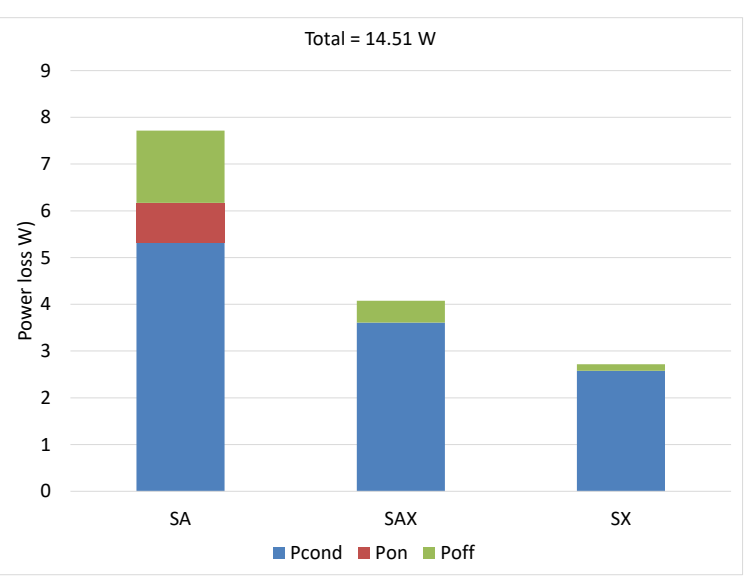

Fig. 10. Losses in the switches of one leg of the converter at its rated power of $3 \mathrm{~kW}$. Because of the ZVS of bottom and middle switches over entire line-cycle, the total loss in MOSFETs reduced to $1.4 \%$ of rated power, as compared to $2 \%$ of rated power in the previous work.

converter. Fig. 15 shows the resonant tank currents or the lower terminal currents, the frequency of which is same as the switching frequency of $60 \mathrm{kHz}$. The interleaved operation of the three DC-DC half-bridges are clearly depicted here by the $120^{\circ}$ phase shift of three resonant tank currents. Note that the positive peak of the resonant tank currents in Fig. 15 are greater than that of the phase currents in Figs. 13 and 14, a requirement for full-range ZVS of the bottom and the middle switches of the nine-switch converter, as discussed before.

Fig. 16 shows the ZVS turn-on of the three switches of a leg of the converter near the peak of the corresponding phase current $(\theta \approx \pi / 2)$ at full load operation. As discussed before, $\theta \approx \pi / 2$ is the most critical area where the bottom and the middle switches might lose ZVS if the proposed design is not followed. It can be seen in Fig. 16 that the bottom switch achieves ZVS because the resonant tank current peak is higher than the phase current before the turn-on of the 


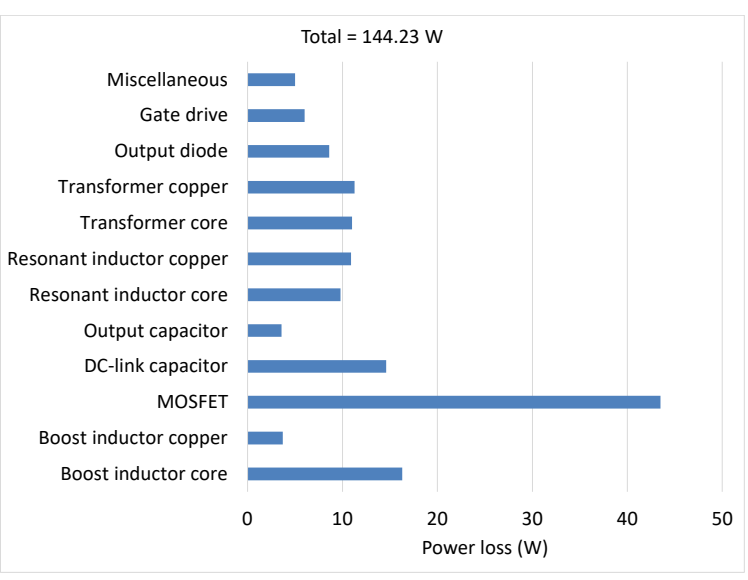

Fig. 11. Distribution of power losses at different components of the converter at its rated power of $3 \mathrm{~kW}$

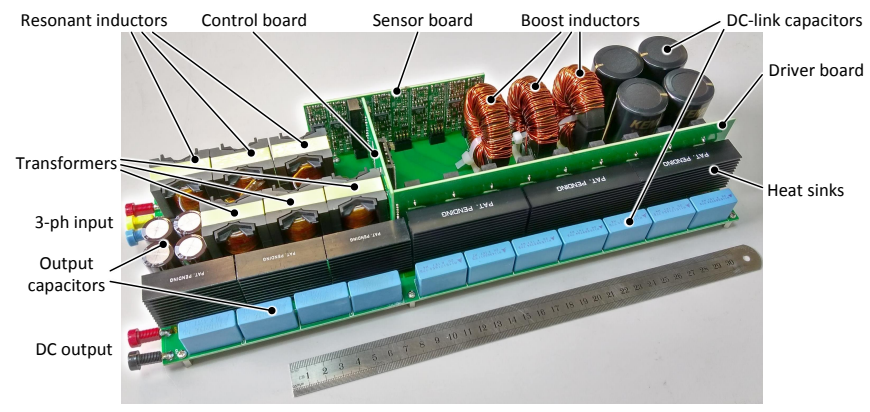

Fig. 12. Laboratory prototype of the nine-switch single-stage three-phase AC-DC isolated converter for $3 \mathrm{~kW}$ rated power.

bottom switch. Similarly, the ZVS turn-on of the middle switch is assisted by the small negative magnetizing current. The experimental demonstration of the soft-switching in the other regions of the line-cycle and at lower load operations has been presented in [15], and therefore, are not repeated here. This verifies the claim in Section IV that with the proposed design methodology, the bottom and the middle switches of the nine-

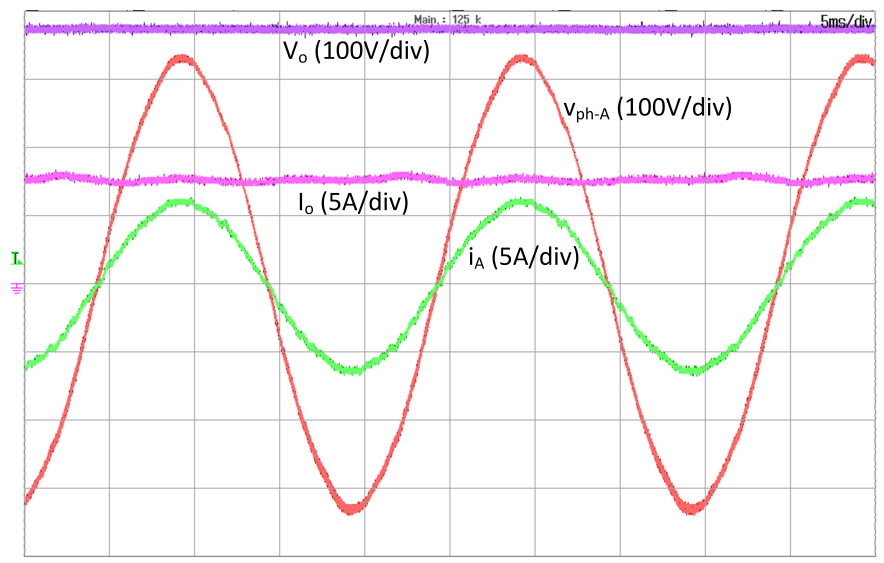

Fig. 13. Key input-output waveforms of the converter showing unity power factor operation at its rated power of $3 \mathrm{~kW}$.

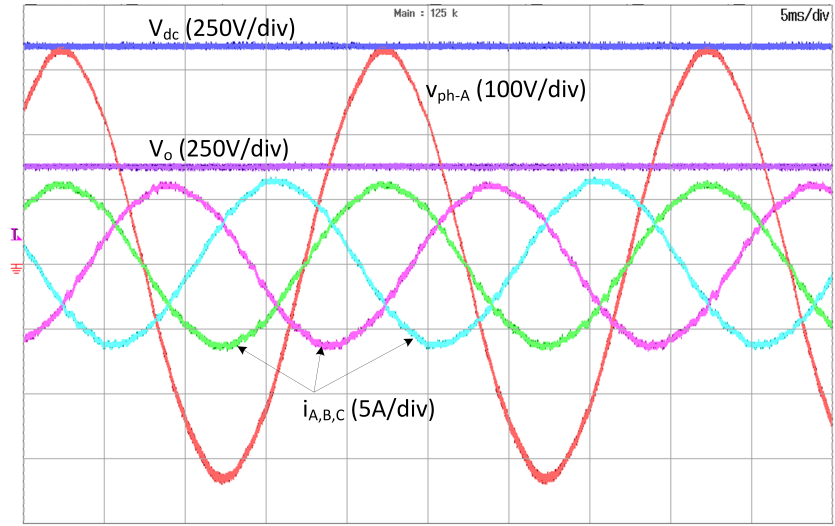

Fig. 14. Three-phase input currents and phase-a voltage along with the DClink voltage and the output DC voltage of the converter at full load operation.

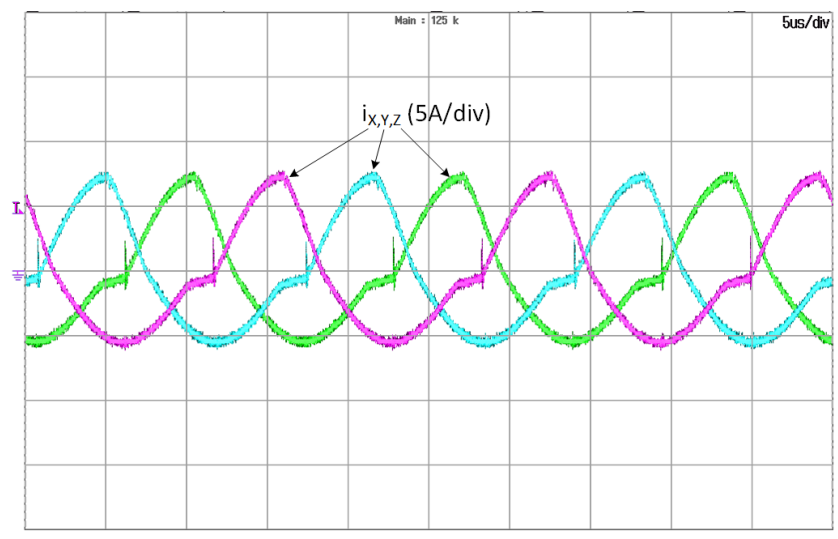

Fig. 15. Resonant tank currents of the converter showing interleaved operation of the DC-DC stages. Note that the frequency of the currents is same as the switching frequency of $60 \mathrm{kHz}$.

switch single-stage AC-DC isolated converter achieve ZVS in the entire line-cycle for all loading conditions.

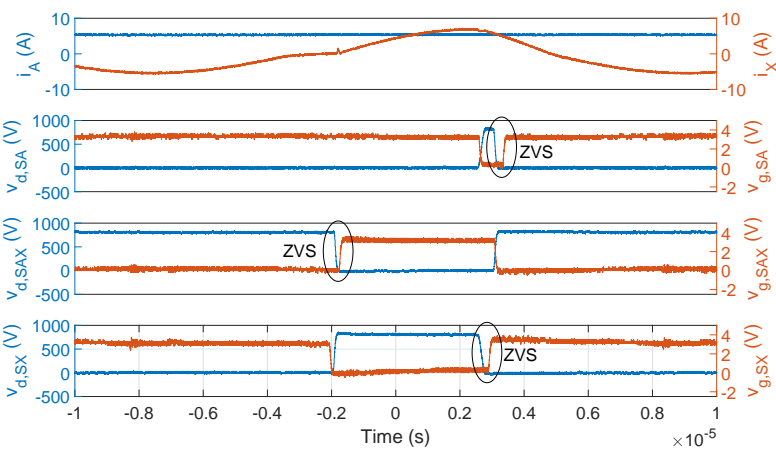

Fig. 16. Experimental demonstration of ZVS of the three switches in the first leg of the converter near the positive peak of the phase-a input current $(\theta \approx \pi / 2)$.

To evaluate the input current THD performance of the converter, a fast fourier transform (FFT) analysis was performed on the captured input current waveform in MATLAB. The obtained harmonic profiles at full load and 50\% load are presented in Fig. 17, which shows that all the harmonic com- 
ponents are below the limits of IEC 61000-3-2 standard for Class A type loads in both cases. The THD of the input current in both full load and 50\% load operations are well within the 5\% limit required for data center loads. This validates the analytical claim presented in Section IV that, the input current THD of the nine-switch converter can be reduced, without the need of increasing the switching frequency, by ensuring ZVS of the bottom and the middle switches in the entire line-cycle. It may be noted here that the reported input current THD of the nine-switch converter in [15] operating at the same switching frequency of $60 \mathrm{kHz}$ (as in this paper) is $6.12 \%$ at full load, where the bottom and the middle switches do not have ZVS at certain regions of the line-cycle.

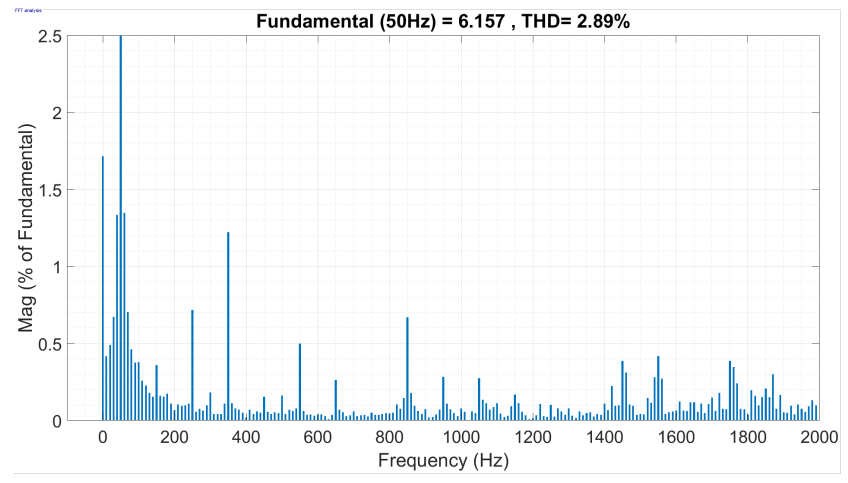

(a) At full load.

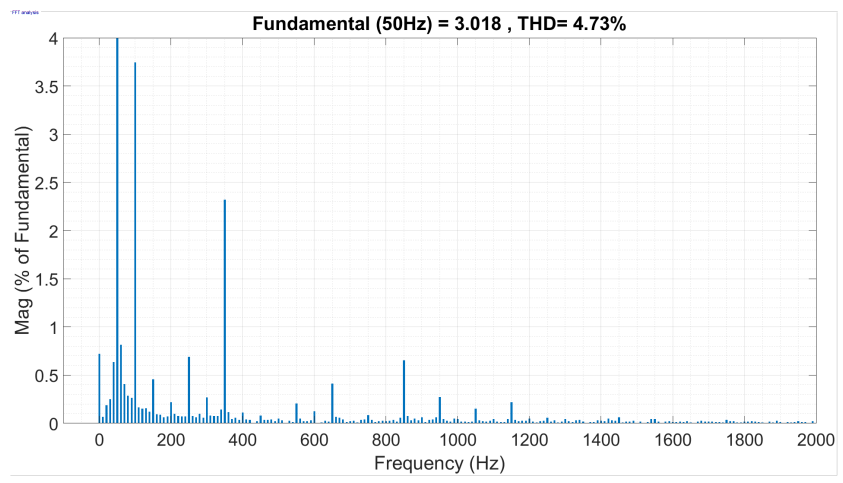

(b) At $50 \%$ load.

Fig. 17. Input current harmonic profiles of the converter up to 40 harmonics. Note that the corresponding THD values in the previous work were $6.12 \%$ at full-load and $7.52 \%$ at $50 \%$ load.

Fig. 18 shows the measured efficiency of the converter for different load power. The peak efficiency is noted as $95.4 \%$.

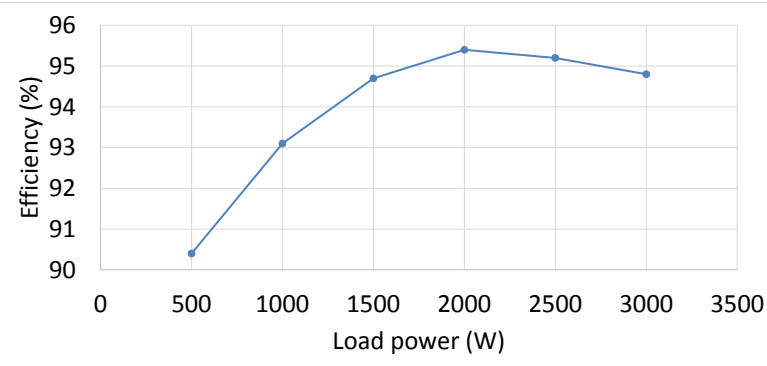

Fig. 18. Measured efficiency of the converter for different load power.

\section{PERFORMANCE COMPARISON}

To highlight the effect of proper choice of $D$, a performance comparison is needed for the two cases - with $D<0.3$, and with $D>0.3$. However, the converter discussed here cannot be compared directly with the one in [15] because the two converters have different specifications (input voltage, output voltage, DC-link voltage and rated power). To have a fair comparison, it is important to obtain the results with the same specifications for the two cases, as has been done in Table VI. Evidently, both the cases with $D<0.3$ (case2 and case4) show better efficiency, lower current THD, and lower DC-link voltage than their counterparts with $D>0.3$ (case1 and case3 respectively).

Table VII shows a performance comparison of the proposed converter with some recently published AC-DC isolated converters with similar range of output voltage and power rating. It is clear that the proposed converter is better than all the three single-stage converters [5], [35], [36] in almost all respects efficiency, current THD, device count, and ZVS of MOSFETs. The Taipei rectifier [5] has $0.79 \%$ lower current THD, but it comes at the cost of a large variation in switching frequency $(18-300 \mathrm{kHz})$ which complicates the magnetics design. The electromagnetic interference (EMI) filter and other magnetic parts of the Taipei rectifier are to be designed for $18 \mathrm{kHz}$ (minimum) frequency that results in bigger foot prints of these components. Similarly, lack of inherent ZVS, high peak current related turn off loss, and use of resistor-capacitor-diode (RCD) clamping circuits limit the frequency of operation of the converter in [36] at $40 \mathrm{kHz}$, resulting in larger size of the magnetic elements.

An equivalent two-stage twelve-switch back-to-back converter is also considered in Table VII for performance comparison. While it has $1 \%$ greater efficiency and $0.31 \%$ less current THD, the penalty is a $25 \%$ extra device count.

Table VIII shows the comparison of cost of the main switching components required to implement the proposed nine-switch converter vs. the equivalent twelve-switch backto-back converter. The MOSFETs are rated at a blocking voltage of 1.5 times the DC-link voltage of the corresponding converter $(600 \mathrm{~V}$ for twelve-switch converter and $800 \mathrm{~V}$ for nine-switch converter). The RMS currents of the switches in a leg for the nine-switch converter are [4.0A, 3.2A, 4.0A], and those of the switches in an equivalent leg for the twelveswitch converter are [3.1A, 3.1A, 2.0A $2.0 \mathrm{~A}]$. Therefore, the continuous current rating of the MOSFETs are selected around $10 \mathrm{~A}$ (which is the cheapest option available) for both the converters. Clearly, even though the nine-switch converter requires a costlier MOSFET, overall there is a possibility of $12.7 \%$ cost saving for the switches and drive electronics as compared to the twelve-switch converter.

\section{CONCLUSIONS}

The interaction between the upper terminal current and the lower terminal current affects the currents through the three switches of a leg in a nine-switch converter. A proper understanding of this interaction is therefore crucial for harnessing the best performance out of this converter. This paper has 
TABLE VI

COMPARISON WITH CASES HAVING $D>0.3$

\begin{tabular}{|c|c|c|c|c|c|c|}
\hline Case & Converter specifications $\left(v_{s}, V_{o}, P_{o}, f_{s}\right)$ & Design specifications & DC-link voltage $\left(V_{d c}\right)$ & Current THD (full-load) & Full-load efficiency & Comment \\
\hline Case1 [15] & $v_{s}=210 \mathrm{~V}, V_{o}=48 \mathrm{~V}, P_{o}=1.5 \mathrm{~kW}, f_{s}=60 \mathrm{kHz}$ & $M_{A}=0.6, D=0.35$ & $570 \mathrm{~V}$ & $6.12 \%$ & $93.4 \%$ (measured) & SPWM \\
\hline Case2 & $v_{s}=210 \mathrm{~V}, V_{o}=48 \mathrm{~V}, P_{o}=1.5 \mathrm{~kW}, f_{s}=60 \mathrm{kHz}$ & $M_{A}=0.7, D=0.28$ & $450 \mathrm{~V}$ & $3.18 \%$ & $94.5 \%$ (calculated) & SVPWM \\
\hline Case3 & $v_{s}=400 \mathrm{~V}, V_{o}=380 \mathrm{~V}, P_{o}=3 \mathrm{~kW}, f_{s}=60 \mathrm{kHz}$ & $M_{A}=0.6, D=0.35$ & $1100 \mathrm{~V}$ & $7.63 \%$ & $93.1 \%$ (calculated) & SPWM \\
\hline Case4 (This work) & $v_{s}=400 \mathrm{~V}, V_{o}=380 \mathrm{~V}, P_{o}=3 \mathrm{~kW}, f_{s}=60 \mathrm{kHz}$ & $M_{A}=0.7, D=0.28$ & $800 \mathrm{~V}$ & $2.89 \%$ & $94.8 \%$ (measured) & SVPWM \\
\hline
\end{tabular}

TABLE VII

COMPARISON WITH EXISTING WORKS

\begin{tabular}{|c|c|c|c|c|c|c|c|c|c|}
\hline Converter & $\begin{array}{l}\text { Rated } \\
\text { power }\left(P_{o}\right)\end{array}$ & $\begin{array}{l}\text { Input } \\
\text { voltage }\left(v_{s}\right)\end{array}$ & $\begin{array}{l}\text { Output } \\
\text { voltage }\left(V_{o}\right)\end{array}$ & $\begin{array}{l}\text { Switching } \\
\text { frequency }\left(f_{s}\right)\end{array}$ & $\begin{array}{l}\text { Full-load } \\
\text { efficiency }\end{array}$ & $\begin{array}{l}\text { Current THD } \\
\text { (full-load) }\end{array}$ & Device count & ZVS & Comment \\
\hline $\begin{array}{l}\text { Taipei } \\
\text { Rectifier [5] }\end{array}$ & $2.7 \mathrm{~kW}$ & $180-264 \mathrm{~V}$ & $200-300 \mathrm{~V}$ & $18-300 \mathrm{kHz}$ & $94.4 \%$ & $2.1 \%$ & $\begin{array}{l}4 \text { MOSFETs, } \\
10 \text { diodes }\end{array}$ & All MOSFETs & $\begin{array}{l}\text { DCM, LC type output filter, } \\
\text { larger EMI filter due to higher } \\
\text { noise from high peak currents, } \\
\text { no interleaving present }\end{array}$ \\
\hline $\begin{array}{l}\text { Almeida } \\
\text { et al. [35] }\end{array}$ & $5 \mathrm{~kW}$ & $380 \mathrm{~V}$ & $380 \mathrm{~V}$ & $50 \mathrm{kHz}$ & $92.5 \%$ & $3.2 \%$ & 24 MOSFETs & $\begin{array}{l}12 \text { MOSFETs full range, } \\
12 \text { MOSFETs half range }\end{array}$ & $\begin{array}{l}\text { CCM, C type output filter, } \\
\text { smaller EMI filter size, } \\
\text { interleaved output stage }\end{array}$ \\
\hline $\begin{array}{l}\text { Gangavarapu } \\
\text { et al. [36] }\end{array}$ & $2.0 \mathrm{~kW}$ & $210 \mathrm{~V}$ & $400 \mathrm{~V}$ & $40 \mathrm{kHz}$ & $94.2 \%$ & $4.87 \%$ & $\begin{array}{l}3 \text { MOSFETs, } \\
15 \text { diodes }\end{array}$ & None & $\begin{array}{l}\text { DCM, LC type output filter, } \\
\text { larger EMI filter due to higher } \\
\text { noise from high peak currents } \\
\text { and hard switching, } \\
\text { no interleaving present }\end{array}$ \\
\hline $\begin{array}{l}\text { Twelve-switch } \\
\text { BTB (two-stage) }\end{array}$ & $3 \mathrm{~kW}$ & $400 \mathrm{~V}$ & $380 \mathrm{~V}$ & $60 \mathrm{kHz}$ & $\begin{array}{l}95.8 \% \\
\text { (calculated) }\end{array}$ & $2.58 \%$ & $\begin{array}{l}12 \text { MOSFETS, } \\
6 \text { diodes }\end{array}$ & $\begin{array}{l}9 \text { MOSFETs full range, } \\
3 \text { MOSFETs half range }\end{array}$ & $\begin{array}{l}\text { CCM, C type output filter, } \\
\text { smaller EMI filter size, } \\
\text { interleaved output stage }\end{array}$ \\
\hline This work & $3 \mathrm{~kW}$ & $400 \mathrm{~V}$ & $380 \mathrm{~V}$ & $60 \mathrm{kHz}$ & $94.8 \%$ & $2.89 \%$ & $\begin{array}{l}9 \text { MOSFETS, } \\
6 \text { diodes }\end{array}$ & $\begin{array}{l}6 \text { MOSFETs full range, } \\
3 \text { MOSFETs half range }\end{array}$ & $\begin{array}{l}\text { CCM, C type output filter, } \\
\text { smaller EMI filter size, } \\
\text { interleaved output stage }\end{array}$ \\
\hline
\end{tabular}

TABLE VIII

Cost Comparison of Nine-Switch AND Twelve-Switch Converter

\begin{tabular}{|c|c|c|c|c|c|c|}
\hline \multirow{2}{*}{ Component } & \multicolumn{3}{|c|}{ Nine-switch converter } & \multicolumn{3}{|c|}{ Twelve-switch converter } \\
\hline & Part no. & Part price (USD)* & Line price (USD)* & Part no. & Part price (USD)* & Line price (USD)* \\
\hline MOSFET & C2M0280120D (1200V rating) & 5.41 & 48.72 & C3M0280090D (900V rating) & 3.46 & 41.50 \\
\hline Gate driver & ACPL-P343-500E & 1.77 & 15.94 & ACPL-P343-500E & 1.77 & 21.25 \\
\hline Isolated power supply & MGJ2D121505SC & 6.65 & 59.85 & MGJ2D121505SC & 6.65 & 79.80 \\
\hline Total & & & 124.51 & & & 142.55 \\
\hline
\end{tabular}

shown how to ensure ZVS of the middle and the bottom switches in a nine-switch single-stage three-phase AC-DC isolated converter over the entire line-cycle, by proper choice of its design parameters. The design also reduces the THD of the input currents below 5\%, a requirement for data center loads fed from AC grid. The simulation and experimental results show that with the proposed design the nine-switch single-stage AC-DC isolated converter is able to achieve similar efficiency and current quality as a conventional twostage back-to-back converter, in addition to achieving a lower part-count.

\section{REFERENCES}

[1] W. Feng, P. Mattavelli, and F. C. Lee, "Pulsewidth locked loop (PWLL) for automatic resonant frequency tracking in LLC DC-DC transformer (LLC -DCX)," IEEE Trans. Power Electron., vol. 28, no. 4, pp. 1862 1869, April 2013.

[2] A. Pratt, P. Kumar, and T. V. Aldridge, "Evaluation of 400V DC distribution in telco and data centers to improve energy efficiency," in INTELEC 07 - 29th International Telecommunications Energy Conference, Sept 2007, pp. 32-39.

[3] S. Oliver and V. C. P. Line, "High-voltage DC distribution is key to increased system efficiency and renewable-energy opportunities," Vicor White Paper, 2012.
[4] X. Li and S. Jiang, "Google 48v power architecture," The Applied Power Electronics Conference and Exposition, 2017.

[5] Y. Jang and M. Jovanovic, "The single-stage Taipei rectifier-design consideration and performance evaluation," IEEE Trans. Power Electron., vol. 29, no. 11, pp. 5706-5714, 2014.

[6] H. Wang, Y. Chen, Y. F. Liu, J. Afsharian, and Z. Yang, "A passive current sharing method with common inductor multi-phase LLC resonant converter," IEEE Trans. Power Electron., vol. PP, no. 99, pp. 1-1, 2016.

[7] M. Noah, K. Umetani, J. Imaoka, and M. Yamamoto, "Lagrangian dynamics model and practical implementation of an integrated transformer in multi-phase 1lc resonant converter," IET Power Electron., vol. 11, no. 2, pp. 339-347, 2018.

[8] E. Orietti, P. Mattavelli, G. Spiazzi, C. Adragna, and G. Gattavari, "Current sharing in three-phase llc interleaved resonant converter," Proc. Energy Convers. Congr. and Expo.(ECCE'09), pp. 1145-1152, 2009.

[9] D. S. Wijeratne and G. Moschopoulos, "A comparative study of two buck-type three-phase single-stage ac-dc full-bridge converters," IEEE Trans. Power Electron., vol. 29, no. 4, pp. 1632-1645, April 2014.

[10] B. Tamyurek and D. A. Torrey, "A three-phase unity power factor singlestage AC-DC converter based on an interleaved flyback topology," IEEE Trans. Power Electron., vol. 26, no. 1, pp. 308-318, 2011.

[11] M. Narimani and G. Moschopoulos, "A new interleaved three-phase single-stage pfc AC-DC converter," IEEE Trans. Ind. Electron., vol. 61, no. 2, pp. 648-654, 2014.

[12] L. S. Yang, T. J. Liang, J. F. Chen, and R. L. Lin, "Analysis and design of a novel, single-stage, three-phase ac/dc step-down converter with electrical isolation," IET Power Electron., vol. 1, no. 1, pp. 154-163, March 2008.

[13] Y. Panov, J. G. Cho, and F. C. Lee, "Zero-voltage-switching three- 
phase single-stage power factor correction convertor," IEE Proceedings - Electric Power Applications, vol. 144, no. 5, pp. 343-348, Sep. 1997.

[14] F. . Hamdad and A. K. S. Bhat, "A novel soft-switching high-frequency transformer isolated three-phase ac-to-dc converter with low harmonic distortion," IEEE Trans. Power Electron., vol. 19, no. 1, pp. 35-45, Jan 2004.

[15] K. Ali, R. K. Surapaneni, P. Das, and S. K. Panda, "An SiC-MOSFETbased nine-switch single-stage three-phase ac-dc isolated converter," IEEE Trans. Ind. Electron., vol. 64, no. 11, pp. 9083-9093, Nov 2017.

[16] T. Kominami and Y. Fujimoto, "A novel nine-switch inverter for independent control of two three-phase loads," in Industry Applications Conference, 2007. 42nd IAS Annual Meeting. Conference Record of the 2007 IEEE, Sept 2007, pp. 2346-2350.

[17] C. Liu, B. Wu, N. R. Zargari, D. Xu, and J. Wang, "A novel threephase three-leg AC/AC converter using nine IGBTs," IEEE Trans. Power Electron., vol. 24, no. 5, pp. 1151-1160, May 2009.

[18] S. M. D. Dehnavi, M. Mohamadian, A. Yazdian, and F. Ashrafzadeh, "Space vectors modulation for nine-switch converters," IEEE Trans. Power Electron., vol. 25, no. 6, pp. 1488-1496, June 2010.

[19] F. Gao, L. Zhang, D. Li, P. C. Loh, Y. Tang, and H. Gao, "Optimal pulsewidth modulation of nine-switch converter," IEEE Trans. Power Electron., vol. 25, no. 9, pp. 2331-2343, Sept 2010.

[20] L. Zhang, P. C. Loh, and F. Gao, "An integrated nine-switch power conditioner for power quality enhancement and voltage sag mitigation," IEEE Trans. Power Electron., vol. 27, no. 3, pp. 1177-1190, March 2012.

[21] X. Liu, P. C. Loh, P. Wang, and F. Blaabjerg, "A direct power conversion topology for grid integration of hybrid AC/DC energy resources," IEEE Trans. Ind. Electron., vol. 60, no. 12, pp. 5696-5707, Dec 2013.

[22] Z. Qin, P. C. Loh, and F. Blaabjerg, "Application criteria for nine-switch power conversion systems with improved thermal performance," IEEE Trans. Power Electron., vol. 30, no. 8, pp. 4608-4620, Aug 2015.

[23] M. S. Diab, A. A. Elserougi, A. S. Abdel-Khalik, A. M. Massoud, and S. Ahmed, "A nine-switch-converter-based integrated motor drive and battery charger system for EVs using symmetrical six-phase machines," IEEE Trans. Ind. Electron., vol. 63, no. 9, pp. 5326-5335, Sept 2016.

[24] K. Ali, P. Das, and S. K. Panda, "A special application criterion of the nine-switch converter with reduced conduction loss," IEEE Trans. Ind. Electron., vol. 65, no. 4, pp. 2853-2862, April 2018.

[25] P. K. Jain, A. St-Martin, and G. Edwards, "Asymmetrical pulse-widthmodulated resonant DC/DC converter topologies," IEEE Trans. Power Electron., vol. 11, no. 3, pp. 413-422, May 1996.

[26] K. Ali, P. Das, and S. K. Panda, "Analysis and design of APWM halfbridge series resonant converter with magnetizing current assisted ZVS," IEEE Trans. Ind. Electron., vol. 64, no. 3, pp. 1993-2003, March 2017.

[27] K. Ali, P. Das, and S. K. Panda, "A nine-switch interleaved three-phase ac-dc single stage isolated converter implemented with sic mosfets," in 2015 IEEE International Telecommunications Energy Conference (INTELEC), Oct 2015, pp. 1-6.

[28] A. M. Hava, R. J. Kerkman, and T. A. Lipo, "Simple analytical and graphical methods for carrier-based PWM-VSI drives," IEEE Trans. Power Electron., vol. 14, no. 1, pp. 49-61, Jan 1999.

[29] J. Holtz, "Pulsewidth modulation for electronic power conversion," Proceedings of the IEEE, vol. 82, no. 8, pp. 1194-1214, Aug 1994

[30] S. M. Dehghan, A. Amiri, M. Mohamadian, and M. A. E. Andersen, "Modular space-vector pulse-width modulation for nine-switch converters," IET Power Electron., vol. 6, no. 3, pp. 457-467, March 2013.

[31] "SPRU485A, digital motor control software library," Texas Instruments Inc., pp. 193-204, 2003.

[32] D. G. Holmes and T. A. Lipo, Pulse width modulation for power converters: principles and practice. John Wiley \& Sons, 2003, vol. 18.

[33] Y. Yang, K. Zhou, H. Wang, and F. Blaabjerg, "Analysis and mitigation of dead-time harmonics in the single-phase full-bridge pwm converter with repetitive controllers," IEEE Trans. Ind. Appl., vol. 54, no. 5, pp. 5343-5354, Sep. 2018.

[34] A. Khaligh, J. R. Wells, P. L. Chapman, and P. T. Krein, "Dead-time distortion in generalized selective harmonic control," IEEE Trans. Power Electron., vol. 23, no. 3, pp. 1511-1517, May 2008.

[35] B. R. de Almeida, J. W. M. de Ara $\tilde{A}^{\circ}$ jo, P. P. PraÃßa, and D. de S. Oliveira, "A single-stage three-phase bidirectional ac/dc converter with high-frequency isolation and pfc," IEEE Trans. Power Electron., vol. 33, no. 10, pp. 8298-8307, Oct 2018.

[36] S. Gangavarapu, A. K. Rathore, and D. M. Fulwani, "Three-phase singlestage-isolated cuk-based pfc converter," IEEE Trans. Power Electron., vol. 34, no. 2, pp. 1798-1808, Feb 2019.

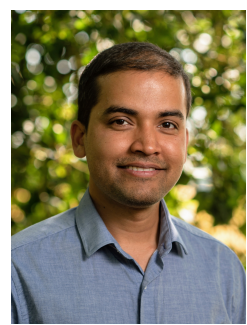

Kawsar Ali (S'14-M'19) received the B. Tech. degree from National Institute of Technology (NIT), Durgapur, India in 2011 and the $\mathrm{PhD}$ degree from National University of Singapore (NUS) in 2018 both in electrical engineering. From 2011 to 2014 he was with the Indian Oil Corporation Limited as an Operations Officer. He joined the Engineering Science Department of the University of Oxford in 2018 as a post-doctoral research associate, where he works on the power electronics design of ultra-low power energy harvesting systems, resonant power conversion, and application of wide-bandgap devices.

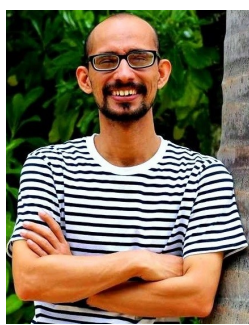

Sunil Kumar Dube received the B.Tech. degree in electrical engineering from National Institute of Technology (NIT), Agartala, India, in 2011, and the M.Tech. degree in power electronics, electrical machines, and drives from Indian Institute of Technology (IIT), Delhi, India, in 2013. From 2013 to 2015 he worked as a Power Delivery Engineer with Intel Technology, Bangalore, India. From 2015 to 2017 he was a PhD student at National University of Singapore (NUS). From 2018 he has been a Graduate Research Assistant at the State University of New York at Binghamton, USA. His research interests include design of high frequency $\mathrm{AC}$ to $\mathrm{DC}$ resonant power converters, bidirectional power converters for battery storage system, and power quality improvement.

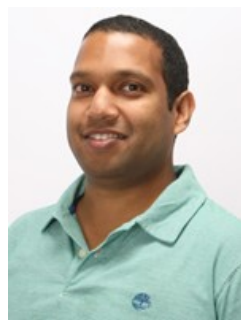

Pritam Das (S'09-M'12-SM'13) received the Master of Applied Science and Ph.D. degrees in electrical engineering from the University of Western Ontario, Canada in 2005 and 2010 respectively. He was a post-doctoral fellow at the Queen's Centre for Energy and Power Electronics Research (ePOWER), Queen's University, Canada from 2010 to 2011; an Electrical Design Engineer at Murata Power Solutions, Toronto, Canada from 2011 to 2013; and an Assistant Professor at the National University of Singapore from 2014 to 2017. In 2018 he joined the State University of New York, Binghamton where he is an Assistant Professor of Electrical and Computer Engineering. He has published over 80 technical papers in refereed journals and conference proceedings and two applied US patents. His current research is focused on developing reliable and high efficiency high-power LED drivers for smart commercial lighting, wide-band gap devices-based power converters for electrified transportation and data centers, and energy storage in smart grid.

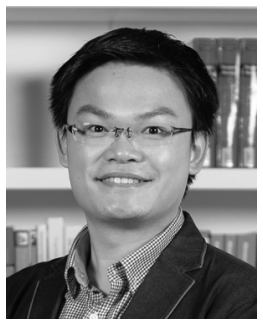

Jimmy Chih-Hsien Peng (S'04-M'12) received the B.E. and Ph.D. degrees in electrical and computer engineering from the University of Auckland, New Zealand, in 2008 and 2012, respectively. He is currently an Assistant Professor in electrical and computer engineering with the National University of Singapore. Previously, he was an Assistant Professor with the Masdar Institute (now part of the Khalifa University), UAE. In 2013, he was appointed as a Visiting Scientist with the Research Laboratory of Electronics, Massachusetts Institute of Technology, USA, where he later became a Visiting Assistant Professor in 2014. He is currently the Secretary of the IEEE Power and Energy Society Working Group on High-Performance Computing for Power Grid Analysis and Operation. $\mathrm{He}$ is also a Committee Member for Singapore Standard SS 535. 


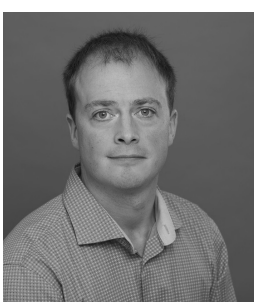

Daniel J. Rogers (M'09-SM'19) is an Associate Professor in the Department of Engineering Science at the University of Oxford, UK. He received the M.Eng. and Ph.D. degrees in Electrical and Electronic Engineering from Imperial College London, London, U.K., in 2007 and 2011 respectively. He conducts research in collaboration with industry and is an investigator on UK EPSRC research projects in the areas of power electronics, grid-scale energy storage and microgrids. Dan's research interests in power electronic range from active control of transistor switching, to circuit and control system design, through to novel applications enabled by wide-bandgap devices. 